\title{
Sudden blindness in a child: presenting symptom of a sphenoid sinus mucocele
}

\author{
I Casteels, E De Loof, P Brock, M Jorissen, L Dralands, L Missotten, G Wilms
}

University Hospitals KU Leuven, B-3000 Leuven, Belgium

\section{Department of Ophthalmology I Casteels \\ L Dralands \\ L Missotten}

Department of Pediatrics E De Loof

P Brock

Department of Oto-rhinolaryngology

M Jorissen

Department of Radiology G Wilms

Correspondence to:

Dr I Casteels, Department of Ophthalmology, Hospital for Sick Children, Great Ormond Accepted for publication 10 February 1992
Figure 1 Lateral plain skull radiograph.

Homogeneous opacification of the sphenoid sinus and abnormal configuration of the sella turcica.

\begin{abstract}
A 10-year-old girl with no nasal or respiratory symptoms developed a headache lasting a few hours. The next day she became totally blind in the right eye and over 5 days vision in the left eye deteriorated to bare light perception. The diagnosis of a sphenoid sinus mucocele was made radiologically and drainage via an endonasal sphenoidectomy produced $12 \mathrm{ml}$ of brownish fluid. Endoscopic biopsy of the wall confirmed the diagnosis of a mucocele. Steroid treatment was given postoperatively, but vision recovered to $6 / 12$ in the left eye only. The importance of urgent clinical diagnosis and treatment is stressed.
\end{abstract}

(Br f Ophthalmol 1992; 76: 502-504)

Mucoceles of the paranasal sinuses were first described by Langenbeck in 1820 under the name hydatides but it was Rollet in 1909 who suggested the name of mucocele. ${ }^{1-3}$ The majority originate in the frontal and anterior ethmoidal sinuses. ${ }^{4}$

Sphenoid sinus mucocele was first reported by Berg in 1889..$^{5}$ The presenting symptoms are variable and depend on the direction of extension into neighbouring structures. Mucocele growth is insidious but they may present acutely with neurological symptoms after expansion and bone destruction. It is a very rare condition in children and diagnostic clues are based on the history, signs of orbital and optic nerve disease and are confirmed by radiological examination.

\section{Case report}

A 10-year-old girl was referred by her ophthalmologist because of bilateral blindness which developed over the previous 5 days. One week earlier she had complained of severe frontal headache for several hours. The next day she

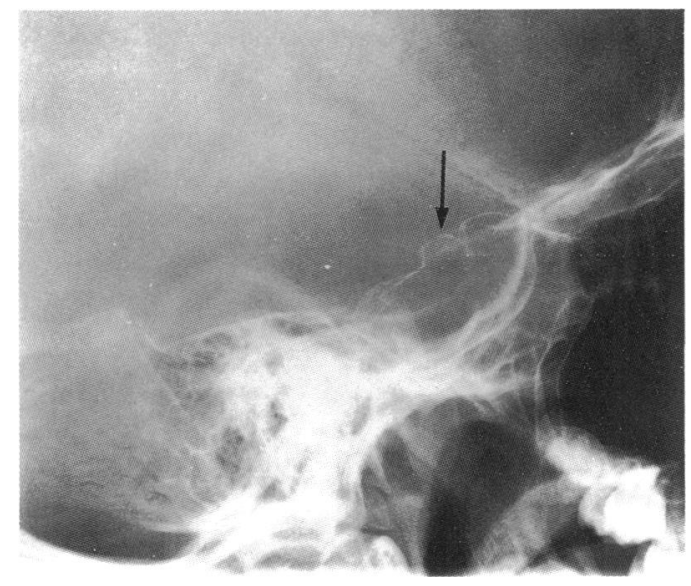

became aware of complete blindness in the right eye, followed by loss of vision in the left eye over the next 5 days. On admission there was no light perception by the right eye and minimal light perception by the left eye, with complete loss of colour perception. Pupillary light reactions were absent in both eyes and the pupils were dilated. Visual field testing was not possible. On funduscopy bilateral symmetrical pallor of the temporal parts of the optic disc without oedema could be seen. The child was in good general health. She did not suffer from any nasal or respiratory problems and general clinical and neurological examination were normal. Routine laboratory testing did not reveal any abnormalities. Analysis of the pituitary gland hormones proved later to be normal.

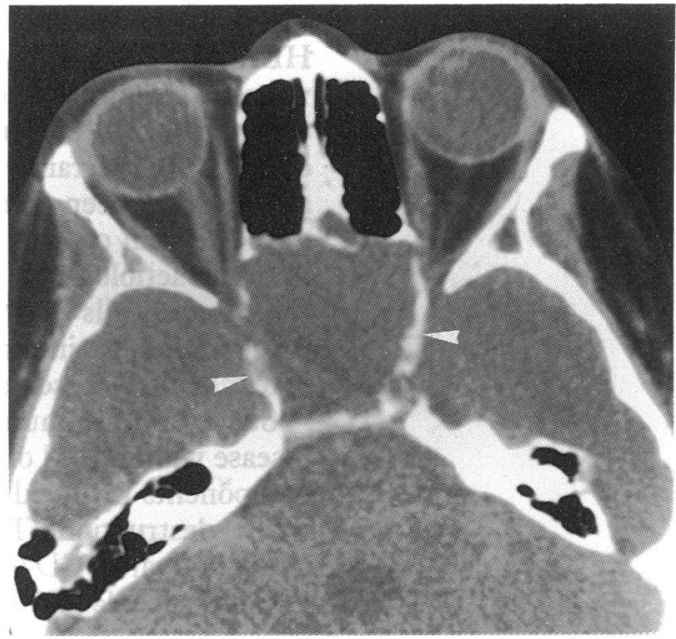

Fig $2 A$

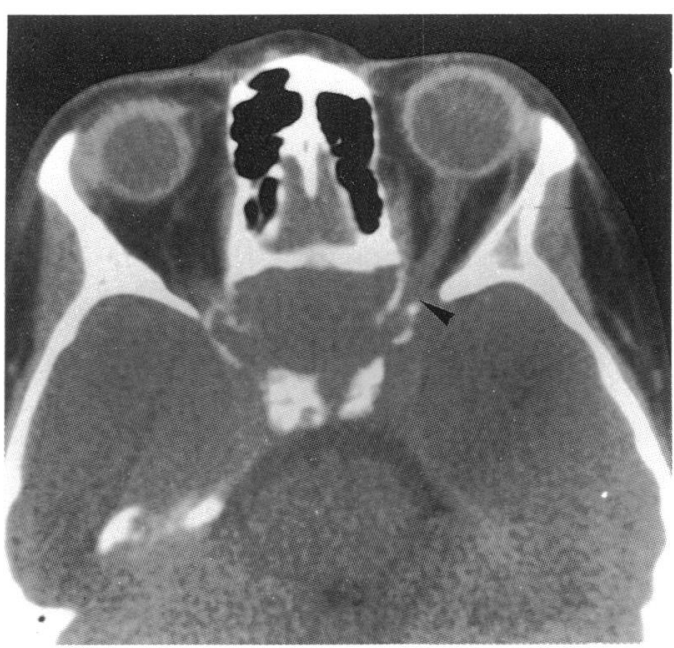

Fig $2 B$

Figure 2 Axial contrast enhanced CT scan. An expanding lesion in the sphenoid sinus with thinning and erosion of the sinus walls $(A)$. Compression of both optic nerves $(B)$. 


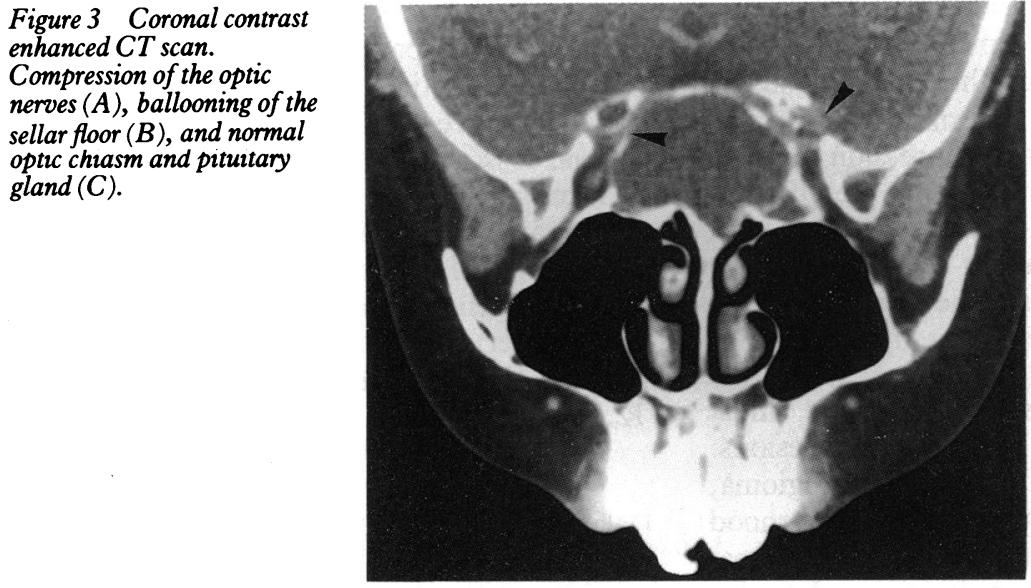

Fig $3 A$

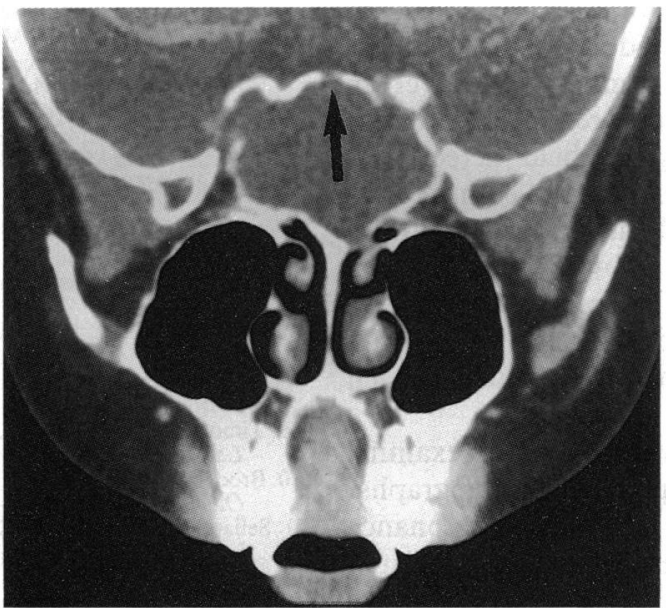

Fig $3 B$

Plain skull radiographs demonstrated a homogeneous opacification of the sphenoid sinus (Fig 1), the sella turcica could not adequately be identified, and ballooning of the sellar floor was suspected. Axial computed tomography (CT) demonstrated a mass lesion in the sphenoid which was approximately isodense with the grey matter of the brain, with thinning and erosion of the sinus walls (Fig 2A, 2B). There was upward erosion with ballooning of the sella and bilateral compression of the optic nerves in the optic canals. The pituitary gland and chiasm appeared normal (Fig 3A, 3B, 3C). A bone marrow smear was normal. As the diagnosis of a sphenoid sinus mucocele was suspected endonasal sphenoidectomy was performed with aspiration of about $12 \mathrm{ml}$ of yellow brown fluid. On endoscopic examination the cavity was lined by a thin mucosal layer without irregularities. Drainage of the sinus was continued for 3 days. Biopsy of the cavity wall confirmed the diagnosis of a mucocele.

Treatment with antibiotics and corticosteroids was initiated. Dexamethasone $2.5 \mathrm{mg} / \mathrm{kg}$, flucloxacillin $70 \mathrm{mg} / \mathrm{kg}$, and amoxycillin $50 \mathrm{mg} /$ $\mathrm{kg}$ were given intravenously at day 2 and day 3 . For the next 2 weeks she was treated with dexamethasone $35 \mathrm{mg} /$ day, flucloxacillin $500 \mathrm{mg} /$ day, and amoxycillin $375 \mathrm{mg} /$ day. The corticotherapy was tapered to zero gradually over the next 2 months. A CT scan after 1 month showed an empty sphenoid sinus. Vision in the left eye recovered to $6 / 24$ after 2 months and 6/12

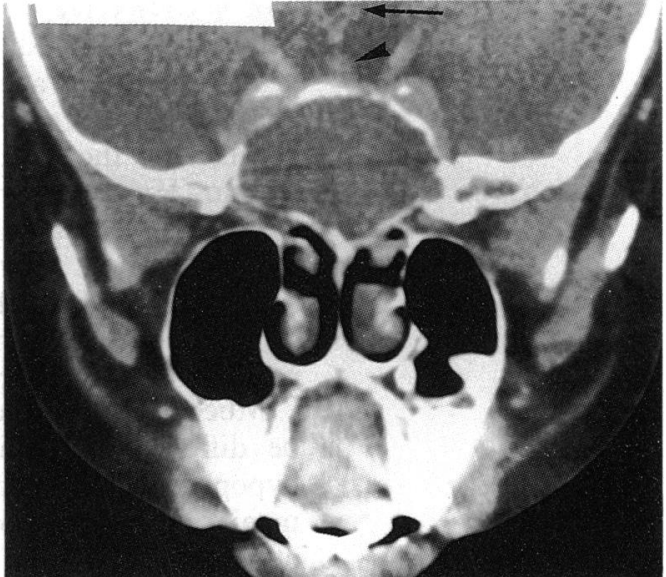

Fig $3 C$

after 3 months. On visual field testing there was a residual relative paracentral scotoma at the left eye. The right eye did not recover; there is no light perception. Complete atrophy of the right optic disc and temporal pallor of the left optic disc were evident.

\section{Discussion}

In young children, slowly progressing visual loss due to chiasmal or optic nerve disease usually presents late because a child compensates quite well a partial or unilateral visual loss. Only when a substantial and bilateral defect has developed do visual problems become obvious. ${ }^{6}$

In our patient the bilateral temporal optic atrophy on admission suggested a longstanding lesion. Blindness was presumably precipitated by a critical increase in the size of the lesion with sudden deterioration of optic nerve function. Lundgren ${ }^{4}$ described 60 adults with sphenoid mucocele with unilateral and bilateral blindness. A recent review of the literature describes the presenting signs and complications of a sphenoidal sinus mucocele in 130 cases. $^{7}$ The youngest patient was 8 years old and presented with exophthalmos. ${ }^{8}$ As these lesions grow very slowly sphenoid sinus mucoceles are rare in children, ${ }^{9}$ and permanent visual loss caused by one is probably exceedingly rare.

A mucocele is a collection of mucus enclosed in a sinus epithelium within an air sinus, resulting from the obstruction of the ostium by inflamed mucosa. Secondary causes of obstruction are a cystic degeneration of an epithelial mucus gland or a cystic degeneration of an inflammatory polyp. However there is a large group in which no cause has been found. ${ }^{10}$

The presenting signs and symptoms of a mucocele originating from the sphenoid are variable and depend on the direction of extension towards neighbouring structures. ${ }^{11-12}$ Headache, facial pain, anosmia, ocular palsy, and visual failure in adults are common, the most consistent being headache, which is usually frontal or retroorbital. Pupil sparing third nerve palsy is described ${ }^{13}$ but paresis of the fourth and sixth cranial nerve is less common; it is caused by the expansion of the mucocele into the cavernous sinus or the superior orbital fissure. Exophthal- 
mos is caused by an invasion in the ethmoidal sinus and lateral displacement of the medial orbital wall. Elevation of the chiasmal sulcus does not produce optic chiasmal field defects because of the lack of compression on the chiasm. Hypopituitarism has been described. ${ }^{14}$ Other symptoms are rhinorrhoea associated with nasal polyposis. Our patient complained of a short period of frontal headache 1 day before the visual loss at the right eye, but the absence of nasal or respiratory problems is noteworthy.

Mucoceles of the sphenoid sinus must be differentiated from the following lesions: hypophyseal tumours, craniopharyngioma, meningioma and glioma in the neighbourhood of the sella turcica, intracranial chordoma, dysgerminoma and cholesteatoma, and finally tumours arising from nasopharynx, sinus, and base of the skull. Erosion of the sellar floor with visual field defects and endocrine disturbances can simulate a pituitary tumour. However an important feature in the differential diagnosis is the absence of a bitemporal field defect in a mucocele because there is no direct compression on the chiasm. ${ }^{4}$ Visual field testing during recovery in our patient showed a paracentral scotoma in the left eye. Differentiation between sphenoid mucoceles and pyoceles or cysts is difficult but the surgical indications and approach are the same.

The sphenoid sinus is difficult to examine clinically and reliance on plain skull radiographs, brain CT, or nuclear magnetic resonance imaging is necessary. ${ }^{15}$ Mucoceles are associated with bone destruction. Bony abnormalities are demonstrable on plain radigraphs using the submentovertical and lateral views. They can be confirmed with a CT scan..$^{10}$ Additional anatomopathological examination of the content confirms the presumed diagnosis of a mucocele.

Sphenoid surgery was first introduced by Schloffer in $1885 .{ }^{16}$ Surgical treatment consists usually of transnasal sphenoidectomy and sinotomy. Other possibilities are transethmoidal, transantral, transpalatal, or trans-septal. Early surgical intervention is essential: if surgery is delayed for more than 6 to 10 days after the start of visual loss and if there is optic atrophy the visual prognosis seems to be poor. Our patient was operated 6 days after she became aware of profound visual loss in the right eye and 1 day after loss of vision in the left eye. After adequate surgical intervention and treatment with corticosteroids the vision recovered in the left eye to $6 / 12$.

1 Alberti PWRM, Marshall HF, Munro Black JI. Frontoethmoidal mucocele as a cause of unilateral proptosis. $\mathrm{Br} \mathcal{F}$ Ophthalmol 1968; 52: 833-8.

2 Vail DT Orbital complications in sinus disease. $A m f$ Ophthalmol 1931; 14: 202-8.

3 Rollet E. In Lagrange F, Vallude E, eds. Paris: Doin Encyclopédie Francaise d'ophtalmologie. 1909; 8: 588

4 Lundgren A, Olin T. Muco-pyocele of sphenoidal sinus or posterior ethmoidal cells with special reference to the apex orbitae syndrome. Acta Otolaryngol (Kbh) 1961; 53: 61-79.

5 Berg J. Bidrag till kannedomen om sjukdomorna i nasans bihalor samt till laran om cerebro-spinal-vatskas flytning ur nasam. Nord Med Ark 1889; 21: 1-24.

6 Taylor D. Pediatric ophthalmology. London: Blackwell, 1990 , 489.

7 Barat J-L, Marchal J-C, Bracard S, Auque J, Lepoire J. Les mucocèles du sinus sphénoidal. Révue de la littérature - A propos de 6 observations personelles. F Neuroradiol 1990; 17: 135-51.

8 Bretange MC, Mole D, Mairey JN, Friot JM, Olive D, Reny $A$, et al. Une cause inhabituelle d'exophthalmie chez A, et al. Une cause inhabituelle d'exophthalmie chez 1978; 59: 305 .

9 Timon CI, O'Dwyer TP. Ethmoidal mucoceles in children. $\mathcal{F}$ Laryngol Otol 1989; 103: 284-6.

10 Brockbank MJ, Brookes GB. The sphenoiditis spectrum. Clin Otolaryngol 1991; 16: 15-20.

11 Sellars SL, De Villiers JC. The sphenoid sinus mucocele. $\mathcal{F}$ Larynol Otol 1981; 95: 493-502.

12 Stanton MB. Sphenoid sinus mucocele. Am $f$ Ophthalmol 1970; 70: $991-4$.

13 Johnson LN, Hepler RS, Yee RD, Batzdorf U. Sphenoid sinus mucocele (anterior clinoid variant) mimicking diabetic ophthalmogi and retrobulbar neuritis. Am $\mathcal{F}$ Ophthalmol 1986; 102: 111-5.

14 Valvassori GE, Putterman AM. Ophthalmological and radiological findings in sphenoidal mucoceles. Arch Ophthalmol 1973; 90: 456-9.

15 Van Tassel P, Lee Y, Jing B, De Pena CA. Mucoceles of the paranasal sinuses: MR imaging with CT correlation. Am $\mathcal{f}$ Neuroradiol 1989; 10: 607-12.

16 Schloffer H. On the nasal route to the sphenoid sinus. $Z$ Klin Chir 1906; 1: 767-817. 